\title{
Environmental Governance in the Coffee Forests of Kodagu, South India
}

\author{
Transforming Cultures eJ ournal, \\ Vol. 3 No 1, February 2008 \\ http:// epress.lib.uts.edu.au/journals/TfC
}

\section{Jeff Neilson $^{1}$}

\begin{abstract}
Place-specific cultural institutions regulate the relationship between coffee planters and the natural world in the Kodagu district of the Western Ghats, a global biodiversity hotspot in South India. Many planters have retained native trees for shade on their plantations, such that these cultivated areas, together with formal protected areas and community-managed sacred groves, constitute a mostly contiguous forested landscape across the district. The integrity of this broader landscape, and the enrolment of coffee planters as environmental stewards, is essential if conservation efforts are to be effective. This paper argues that the required participatory approaches to landscape conservation in this region actually contrast with global certification schemes currently being promoted to enhance sustainability in the coffee industry. The critical issue raised here is the changing scale at which environmental governance systems are being constructed through the corporate re-regulation of global supply chains.
\end{abstract}

\section{Introduction}

Global regulatory shifts in agricultural trade are fundamentally changing the way environmental issues are being addressed by farmers, NGOs, governments and other stakeholders. Concerns over 'green protectionism', as a Technical Barrier to Trade (TBT), have hitherto limited the ability of the World Trade Organisation (WTO) to include environmental standards within bilateral and multilateral trade agreements (McCormick 2006). The awkward position of environmental standards within international trade negotiations, however, is increasingly being resolved through the rise of corporate self-regulation motivated by brand management concerns in consuming markets. According to Graham and Woods (2006: 869), corporate self-regulation

\footnotetext{
${ }^{1}$ Dr Jeffrey Neilson is a Postdoctoral Research Fellow with the School of Geosciences, University of Sydney.
} 
describes "attempts by corporations to establish rule-based constraints on behaviour without the direct coercive intervention of states or other external actors". This paper contrasts supply-chain approaches to sustainability (corporate self-regulation) with participatory, area approaches to landscape conservation and sustainability, using a case-study from a major coffee-producing district in South India.

The implications of increasing global corporate self-regulation for environmental governance are profound, and parallel Swyngedouw's (2000) exploration of the disempowering effects of 'glocalisation' through a rescaling of governance structures and the 'hollowing out' of the state. Indeed, the emergence of 'post-sovereign' environmental governance (Karkkainen 2004) has been presented as arising from the limitations of top-down, territorially defined state structures. However, in many instances, market-based environmental instruments have been added to, rather than supplanted, traditional governance structures, leading to complex and sometimes conflicting practices 'on-the-ground' (Meadowcroft 2002). It would seem that extraterritorial environmental governance, reflected here in an emergent politics of corporate self-regulation, further risks divorcing environmental management from the placespecific contexts of local agro-ecological problems. As argued by Lockie and Goodman (2006), ‘duty of care’ approaches towards environmental management by landholders in Australia, are in sharp contrast to the commodity chain approaches employed (for instance) by the Fairtrade movement.

Community-based natural resource management has become a popular catchphrase within certain development and academic circles. Whilst the uncritical adoption of community management systems has been severely criticised by some observers (see, for example Blaikie 2006), there is also broad recognition of the need to adopt a more participatory approach towards environmental management, particularly in developing country contexts. The apparent failure of state-led environmental governance to deliver the desired outcomes has ushered in a new wave of both community-centred and corporate-driven environmental management strategies. Leading agri-food researchers, such as Harriet Friedmann, are now describing the convergence of environmental and social politics, and the retail-led reorganisation of food supply chains in terms of an emergent 'corporate-environmental food regime' (Friedmann 2005). The rise of marketdriven environmental standards and certification in the contemporary global food 
system, however, appears to offer few concrete mechanisms for the participation of farmers in conservation programs across the developing world. The 'hollowing-out' of the state, it would seem, is critically challenging the ability of established institutional structures to undertake environmental management in many producer communities.

This article first presents the geography of coffee planting and environmental governance structures within the broader agro-ecological and social setting of Kodagu district, introducing both culturally-specific and state-led structures for managing the ecological integrity of the Kodagu forest landscape. These endogenous management systems are then contrasted with the introduction of corporate sustainability codes, established primarily by international coffee companies, seeking to manage brand reputations in consuming markets against allegations of social and environmental neglect. This analysis generates important insights into the potential for ensuring the provision of environmental services in the coffee sector through global market-based initiatives.

\section{Coffee Planting and Conservation in Kodagu}

Coffee has been cultivated in the Western Ghats of India for centuries, and is widely believed to have been introduced from the Yemeni port of Mocha by the Muslim saint, Baba Budan, in the $16^{\text {th }}$ century (Ukers 1935). Some time after its introduction, coffee cultivation was embraced by the Kodavas, the dominant community within the modernday district of Kodagu in Western Karnataka (Richter 1870). Today, more than onethird of India's coffee is grown in Kodagu district (Coffee Board of India 2006), making it the most important growing district in India, the world's fifth largest coffee-producing country.

The Kodavas, also known as Coorgs, are a close-nit social group, with renowned martial and agrarian traditions. The Kodavas generally consider themselves Ksatriya according to the system of Hindu Varnas, and yet their elaborate rituals are closely aligned to forms of nature and ancestor worship rather than following strict Vedic principles (Srinivas 1965). Under certain circumstances, related to their former hunting culture, the Kodavas would even conduct ceremonies symbolically uniting in marriage the spirits of killed tigers with the spirit of the hunter, highlighting the intimate relationship between 
Kodava culture and the wildlife living in their forest realm. Sacred groves, known as devarakadu (devara = God's and kadu = forest), continue to be maintained in their natural state amongst the coffee plantations (Chandrakanth et al. 2004). Each village has at least one devarakadu, which is believed to be an abode of the gods, with strict laws and taboos against poaching and felling of trees (Bhagwat et al. 2005). The groves are also an important storehouse of biodiversity in the district.

Following the British annexation of Kodagu in 1834, large numbers of European planters began settling in the forested mountains to cultivate coffee, dramatically changing the economic and environmental management structures of Kodava society. According to a publication of the United Planters Association of Southern India (UPASI):

“pioneer British planters progressively 'opened up’ the South Indian planting districts for tea and coffee, applying a blueprint from which a thriving industry emerged, and survives until today” (Kariappa et al. 2004: 2).

That early blueprint included the insistence of early pioneers that coffee bushes should be maintained under a dense canopy of shade. The practice of planting coffee in the under-storey of a three-tiered canopy, including an upper canopy of remnant rainforest trees, remains common today. However, coffee industry expansion across Kodagu in the 1970s and 1980s has also taken place at the expense of native vegetation cover (Garcia et.al. 2007). This expansion has been associated with a tendency for native shade trees to be replaced with the exotic silver oak (Grevillea robusta), with severe implications for the habitat value of the estates. For the most part, however, modern Kodagu coffee planters consider themselves environmental stewards, and are even willing to make significant financial contributions to biodiversity conservation on their estates (Ninan and Sathyapalan 2005).

The wealth of biodiversity found in the coffee forests of Kodagu is considerable, and includes some of India's larger flagship species, such as elephants, tigers, bison, leopards, and sambar deer. Conservation International recognises the Western Ghats as one of only 25 global biodiversity 'hotspots' (Myers et al. 2000), and a survey by Bhagwat et al. (2005) found that tree, bird and fungal diversity in Kodagu was 
comparable between coffee plantations and adjacent protected forest and sacred groves. Bhagwat et al. (2005) again emphasises the habitat value of shaded coffee plantations in the Western Ghats, and the need to conserve habitats adjoining protected areas to increase the 'landscape-level connectivity' of patches. Maintaining the ecological integrity of coffee plantations, within a broader landscape of formal protected areas and devarakadu groves, is undoubtedly a vital component of wider biodiversity conservation efforts in the region.

\section{Area Approaches to Conservation in Kodagu}

An estimated two-thirds of Kodagu district is covered by forest (Chandrakanth et al. 2004), which includes the coffee plantations, devarakadu groves, three Wildlife Sanctuaries (Brahmagiri, Talakaveri and Pushpagiri), and one National Park (Nagarahole). These formal protected areas further constitute site elements within the Talacauvery sub-cluster nomination for World Heritage recognition (UNESCO 2007). In densely populated India, tensions between the resource needs of local communities and wildlife objectives are ubiquitous. There are fundamental conflicts between local communities and the organisation entrusted with formal wildlife management in India, the Indian Forest Service. These tensions severely complicate a traditional, exclusionary approach to conservation efforts in India (Mahanty 2002; Arjunan et al. 2006), highlighting the reality that formal protection is likely to remain only one element, albeit an integral one, within a broader approach to conservation in strategic ecological sites such as Kodagu.

Settlements in Kodagu are not generally comprised of condensed village units, as is common in other parts of rural India. Instead, Okka family groups are scattered across agricultural and forested holdings, where traditional ainemane houses form focal meeting points in the rural landscape. The emergence of townships, as such, has been a relatively recent phenomenon and many of the main towns in Kodagu are inhabited by recent migrants and non-Kodavas. A system of land tenure, known as Jamma, was formerly instituted in Kodagu during the pre-colonial Paleri Dynasty of the Lingayat Rajas (Srinivas 1965). Jamma agricultural lands (generally reserved for wet-rice cultivation) were held almost exclusively by Kodavas as a hereditary right, and were both indivisible and inalienable. Importantly, rights over the adjacent forests (bane) 
were also attached to Jamma tenure, such that relatively expansive agricultural-forestry estates have remained intact across Kodagu. The exclusion of plantation crops, such as coffee, from India's Land Ceiling Act has further insulated these holdings from postindependence land reform efforts across India. Importantly, rights over the adjacent forests (bane) were also attached to Jamma tenure, such that relatively expansive agricultural-forestry estates have remained intact across Kodagu. A unique feature of Jamma tenure is that tree rights remained with the Rajas, and were subsequently transferred to the colonial and post-independence governments and remains an import determinant of landuse practices in the district. The exclusion of plantation crops, such as coffee, from India's Land Ceiling Act has further insulated these holdings from postindependence land reform efforts across India.

The complexity of land tenure in Kodagu is such that tree rights on unredeemed coffee plantations (and in the Jamma Malais cardamom forests) remain in the hands of the government (Uthappa 2004). Whilst these restrictions are a continuing source of tension in the community (The Hindu 2006), they do appear to have helped protect the biodiversity of trees, birds and other biota on the plantations, and have halted the replacement of native trees by exotic fast growing shade trees. Uthappa (2004) has highlighted, in great detail, the influence of local institutional structures, embedded within land tenures, across Kodagu on conservation practices in the district. These institutions clearly demand an explicitly geographical approach to conservation efforts.

In 2005, Kodagu joined the International Model Forest Network (IMFN²), a global partnership aimed at developing a participatory approach to sustainable forest-based landscape management. The Kodagu Model Forest Trust (KMFT) has been established to facilitate a voluntary, partnership-based approach to managing the entire Kodagu landscape, encompassing protected areas, coffee plantations, wet-rice agriculture and riverine ecosystems. The active involvement of coffee planters will be integral to the success of the KMFT. Attempts are being made to address issues related to land tenure, shade tree management, appropriate remuneration for producers, and payments for environmental services. The clear point to be made here about this initiative is the explicitly landscape approach to sustainability, which identifies priorities and strategic action plans against geographically-informed criteria specific to the Kodagu context.

\footnotetext{
${ }^{2}$ The IMFN secretariat is located in Ottawa, Canada.
} 


\section{Supply Chain Sustainability}

A contrasting approach to fostering environmental sustainability is the introduction of corporate self-regulation, which is built around an argument of enhanced shareholder value through effective risk management (Brown and Fraser 2006). The doctrine of Corporate Social Responsibility (CSR) has expanded rapidly since the 1990s, and has had a particularly visible presence within the global coffee sector. Implicit to the argument in favour of private environmental regulation is distrust of the regulatory capacity of the state, particularly in developing countries such as India.

Elsewhere Neilson and Pritchard (2007) have described the mechanics of corporate engagement with sustainable coffee agendas as occurring via three overlapping sets of processes: (i) corporate adoption of NGO-certified 'niche' product lines; (ii) the development of firm specific corporate codes of conduct, and (iii) an agenda to work towards collective private standards for the industry as a whole. Inherent to this engagement has been the trend toward supply chain traceability, as corporate coffee companies attempt to distance their particular brands from allegations of systemic poverty, chronically low-prices and environmental destruction (Charveriat 2001; Gresser and Tickell 2002; Robbins 2003). According to this framework, the initial adoption of organic and fair-trade product lines has gradually given way to the development of industry-wide agreements. In the coffee sector, key industry initiatives include the Euro-Retailer Produce Working Group (EUREP) protocols for Good Agricultural Practice (EUREP-GAP, but since September 2007 known as GlobalGAP), which (for coffee) is increasingly associated with Utz Kapeh certification, and the 'Common Code for the Coffee Community', widely known as '4C'. Coffee producers are now finding that Utz Kapeh certification is becoming a mandatory requirement to sell to certain buyers, especially in the European market.

The Indian coffee industry has been a consistently vocal critic of global attempts to link certification and traceability with market access (Menon 2005; Venkatachalam 2005; Neilson and Pritchard 2007). Whereas the primary aim of earlier 'bird-friendly', 'shadegrown' and otherwise ecologically sound coffees was to reward producers for environmental services, it is likely that industry-wide codes are actually threatening the ability of producers to generate economic rents through product differentiation (Mutersbaugh 2005). It is important to remember that the growth of corporate self- 
regulation in the global coffee sector has been driven by a business argument for effective risk management and the increasing value of leading brands. It is prudent, therefore, to maintain a healthy scepticism towards the capacity of supply chain approaches to effectively contribute to environmental improvements in producing communities. The environmental benefits of market-based price premiums for ecofriendly production practices in low-income countries have been questioned by Ferraro et al. (2005). Through economic modelling, Ferraro et al. (2005) show that such indirect premiums are less effective than direct payments made to land managers, thereby questioning whether market incentives are the most efficient use of funding by conservation agencies.

Due to their inherently global scope, initiatives such as Utz Kapeh, 4C, or the Starbucks CAFÉ Practices $^{3}$ scheme, rely on a check-list approach to social and environmental responsibility. Suppliers (producers) are audited against compliance to specific environmental criteria such as 'watercourse protection', 'maintaining shade cover', 'protecting wildlife', or the existence of a 'conservation management plan'. It is expected that buyer-imposed adherence to such criteria will eventually lead to improved environmental performance. In this way, corporate codes of conduct may help address the worst forms of environmental abuse, although they are likely to be of little benefit to conservation efforts in places such as Kodagu. An inherent assumption of a global code is that environmental conditions in various producing localities can be fairly assessed in a comparative way. For the most part, however, the heavily-shaded coffee plantations of Kodagu exceed the requirements of these generic codes, and cannot really be equated with the more open-canopied coffee systems found in Brazil, Vietnam, Indonesia and elsewhere. The introduction of 'lowest common denominator' global-scale coffee codes is aimed at protecting brand reputations at the consumer level, whilst simultaneously threatens to limit the capacity for product differentiation and market premiums to be used for effective biodiversity conservation. In many cases, traceability-driven codes of conduct allow branded coffee companies to maintain control over the means for quality construction at the consumer level, thereby maintaining significant economic rents (Neilson 2007).

\footnotetext{
${ }^{3}$ Coffee And Farmer Equity
} 


\section{Conclusion}

The rise of corporate self regulation has far-reaching implications for global environmental governance. Associated with the 'hollowing out' of the state, CSR initiatives are increasingly defining the boundaries of acceptable and unacceptable social and environmental performance in a way which both pre-empts and displaces state intervention. This implies a shift in environmental governance away from the local scale towards globally-defined systems and structures. The purpose of this paper has been to underline the risks associated with constructing environmental management systems at a global scale. In many cases, these systems cannot adequately compensate for the diversity of institutional forms found in local geographical settings. In Kodagu, such institutions include Jamma tenure arrangements, cultural and religious belief systems, human-wildlife interactions and protected area management. When the standards are being set by organisations with clearly defined commercial objectives, corporate self regulation further removes the capacity for producer-driven product differentiation.

Importantly in the case of South India, Ninan and Sathyapalan (2005) emphasise that the positive attitude of the planter community towards biodiversity conservation is contingent on their inclusion within strategic planning from the outset. The imposition of an externally-dictated management regime on the planter is less likely to receive widespread support. The perceived loss of local planter control to global environmental dictates may, counterproductively, undermine local social institutions leading to declining stewardship sentiments.

\section{Bibliography}

Arjunan, M., Holmes, C., Puyravaud, J-P., Davidar, P. (2006) 'Do developmental initiatives influence local attitudes toward conservation? A case study from the Kalakad-Mundanthurai Tiger Reserve, India'. Journal of Environmental Management 79(2 ): 188-197.

Bhagwat, S.A.; Kushalappa, C.G.; Williams, P.H. and Brown, N.D. (2005) 'A Landscape Approach to Biodiversity Conservation of Sacred Groves in the Western Ghats of India’, Conservation Biology 19 (6): 1853-1862.

Blaikie, P. (2006) 'Is small really beautiful? Community-based natural resource management in Malawi and Botswana’, World Development 34(11): 1942-1957. 
Brown, J. and Fraser, M. (2006) 'Approaches and Perspectives in Social and Environmental Accounting: an Overview of the Conceptual Landscape'. Business Strategy and the Environment 15(2): 103-117.

Chandrakanth, M.G., Bhat, M. G. and Accavva, M. S. (2004) 'Socio-economic changes and sacred groves in South India: Protecting a community-based resource management institution', Natural Resources Forum 28 (2): 102-111.

Charveriat, C. (2001) Bitter Coffee: How the Poor are paying for the slump in world coffee prices. London: Oxfam International.

Coffee Board of India (2006) Database on Coffee. Bangalore: Economic \& Market Intelligence Unit Coffee Board.

Damodaran, A. (2002) 'Conflict of Trade-Facilitating Environmental Regulations with Biodiversity Concerns: The Case of Coffee-Farming Units in India', World Development 30 (7): 1123-1135.

Ferraro, P.J., Uchida, T. and Conrad, J.M. (2005) Price Premiums for Eco-friendly Commodities: Are 'Green' Markets the Best Way to Protect Endangered Ecosystems? Environmental \& Resource Economics 32 (3): 419-438.

Friedmann, H. (2005) 'From Colonialism to Green capitalism: Social movements and emergence of food regimes', New Directions in the Sociology of Global Development (eds. Buttel, F. and McMichael, P.). Oxford: Elsevier.

Garcia, C., Marie-Vivien, D., Kushalappa, C. G., Chengappa, P. G., and Nanaya, K.M. (2007) 'Geographical Indications and Biodiversity in the Western Ghats: Can labelling benefit producers and the environment in a mountain agroforestry landscape?’ Mountain Research and Development, 27 (3), pp206-210

Graham, D. and Woods, N. (2006) 'Making Corporate Self-Regulation Effective in Developing Countries’. World Development 34(5): 868-883.

Gresser, C. and Tickell, S. (2002) Mugged: Poverty in your coffee cup. Oxfam International Report, available at <www.maketradefair.com>.

Hobbs, J.E. and Kerr, W. A. (2006) 'Consumer information, labelling and international trade in agri-food products’, Food Policy 31 (1): 78-89.

Kariappa, C.P., Dhunjeebhoy, H.D., Ramaswamy, V., and Datta, A. (2004) Planting Times, MacMillan and UPASI, Bangalore.

Karkkainen, B. C. (2004) 'Post-Sovereign Environmental Governance', Global Environmental Politics 4(1): 72-96.

Lockie, S. and Goodman, M. (2006) 'Neoliberalism and the Problem of Space: Competing Rationalities of Governance in Fair Trade and Mainstream AgriEnvironmental Networks', Research in Rural Sociology and Development (Vol. 12). Oxford: Elsevier: 95-117.

Mahanty, A. (2002) Conservation and development interventions as networks: The case of the India eco-development project, Karnataka, World Development 30 (8): 1369-1386.

McCormick, R. (2006) 'A Qualitative Analysis of the WTO's Role on Trade and Environment Issues’, Global Environmental Politics 6(1): 102-124.

Meadowcroft, J. (2002) 'Politics and scale: some implications for environmental governance', Landscape and Urban Planning 61 (2-4): 169-179. 
Menon, U. (2005) 'Foresee 4c Foxy’ (editorial), Planters Chronicle 101 (10) in Journal of the United Planters' Association of Southern India (UPASI): 1.

Mutersbaugh, T. (2005) 'Fighting standards with standards: harmonization, rents and social accountability in certified agrofood networks', Environment and Planning A 37(11): 2033-2051.

Myers, N.; Mittermeier, R.A.; Mittermeier, C.G.; da Fonseca, G.A.B. and Kent, J. (2000) 'Biodiversity hotspots for conservation priorities', Nature 403 (February 24): 853-858.

Neilson, J. (2007) 'Institutions, the Governance of Quality and On-Farm Value Retention for Indonesian Specialty Coffee', Singapore Journal of Tropical Geography 28(2), pp 188-204.

Neilson, J. and Pritchard, B. (2007) 'Green Coffee: Contestations over global sustainability initiatives in the Indian coffee industry', Development Policy Review, 25(3), pp 311-331.

Ninan, K.N. and Sathyapalan, J. (2005) 'The economics of biodiversity conservation: a study of a coffee growing region in the Western Ghats of India', Ecological Economics 55 (1): 61-72.

Richter, G. (1870) Gazetteer of Coorg: Natural Features of the Country and the Social and Political Condition of its Inhabitants. Reprinted 2002, New Delhi: Low price Publications.

Robbins, P. (2003) Stolen Fruit: The Tropical Commodities Disaster. London: Palgrave Macmillan.

Srinivas, M. N. (1965) Religion and Society among the Coorgs of South India. Bombay: Asia Publishing House.

Swyngedouw, E. (2000) 'Authoritarian governance, power, and the politics of rescaling', Environment and Planning D: Society and Space 18 (2000): 63-76.

The Hindu (2006) 'Meeting on tree rights a farce, says committee'. 12/11/2006. Available at: <www.thehindu.com/2006/11/12/stories/2006111210920300.htm>

Ukers, W. H. (1935) All About Coffee. New York: The Tea and Coffee Trade Journal Company.

UNESCO (2007) World Heritage Centre Tentative List, Reference No. 2203, Date of Submission 15/03/2006, Available at <http://whc.unesco.org/en/tentativelist> (accessed February 2, 2007).

United Planters of Southern India (2005) Year Book and Annual Report 2004-05. Coonoor (India): UPASI.

Uthappa, K.G. (2004) Land Tenure, Land Holding, and Tree Rights of Kodagu. Ponnampet: Kodagu Model Forest Trust.

Venkatachalam, L. (2005) Perspectives on Sustainability and Globalization and the challenges for the coffee sector. Proceedings of the 2nd World Coffee Conference, 23-25 September, Salvador, Brazil (available at <http://www.ico.org/event_pdfs/wcc2/presentations/venkatachalam.pdf>. 